\title{
Modified approach for harmonic reduction in three-phase to seven-phase using transformer winding connections
}

\author{
Mehrdad Ahmadi Kamarposhti ${ }^{1}$, Ashkan Abyar Hosseyni ${ }^{2}$ \\ ${ }^{1}$ Department of Electrical Engineering, Jouybar Branch, Islamic Azad University, Iran \\ ${ }^{2}$ Department of Electrical Engineering, University College of Rouzbahan, Iran
}

\begin{tabular}{l} 
Article Info \\
\hline Article history: \\
Received May 15, 2018 \\
Revised Nov 23, 2018 \\
Accepted Dec 12, 2018 \\
\hline
\end{tabular}

Keywords:

Harmonic reduction Multiphase power transformer Seven-phase Special transformer Three-phase Winding connections

\begin{abstract}
Three phase supply is available in the generating station or grid, were as seven phase supply is required for many industrial applications such as, aerospace, railway and automobile applications. There are different methods in which we can convert 3 to 7 phase using 24-Pulse Converter, Carrier Based PWM Technique, multilevel converter and Multiphase Transformer. The above said methods which are more complicated to design for higher ratings or a pure sine wave will not be obtained or harmonics will be more. For Multiphase power transmission system multiphase transformers are needed. In the multiphase power transmission and multiphase rectifier systems, the number of phase can be designed and developed in multiples of three. Therefore, the variable speed multiphase drive system considered in the literature are mostly of five, seven, nine, eleven, twelve, and fifteen phase. So, there is a need to design and develop special transformer which converts from 3 to 7 phase for different arrangement of input and output. Thus, with the proposed technique, a pure seven-phase sine-wave of fixed voltage/current and frequency is obtained, which can be used for RL load and motor testing purposes. Complete design and simulation of the proposed solution is presented. Analytical calculation and simulation results for RL load is presented in the paper. This model can be simulated by using Orcad simulation software and "SimPowerSystem" block sets of MATLAB/SIMULINK software.
\end{abstract}

Copyright $\odot 2019$ Institute of Advanced Engineering and Science. All rights reserved.

\section{Corresponding Author:}

Mehrdad Ahmadi Kamarposhti,

Department of Electrical Engineering,

Jouybar Branch, Islamic Azad University,

Jouybar, Iran.

Emails: m.ahmadi@jouybariau.ac.ir,mehrdad.ahmadi.k@gmail.com

\section{INTRODUCTION}

Multi-phase (more than three-phase) systems have received much attention of researchers in recent times due to their inherent advantages when compared with the conventional three-phase counterpart. The applicability of multi-phase systems is investigated in electric power generation [1-2], transmission [3-4] and utilization [5-7]. The research on six-phase transmission system was initiated due to rising cost of right of way for transmission corridors, environmental issues and various stringent licensing laws. Six-phase transmission lines can provide the same power capacity with a lower phase to phase voltage and smaller, more compact towers as compared to a standard double circuit three-phase line. The geometry of the six-phase compact towers may also aid in the reduction of magnetic fields and thus electromagnetic interference issues as well [3].

The research on multi-phase generators have started recently [1-2]. Multi-phase systems are mostly the subject of interest in variable speed motor drive applications. Research on multiphase drive is mostly focused on five-phase and six-phase systems with the objective of developing highly reliable and efficient 
drive system. The research results on multi-phase drives are summarized in [7-8]. It is to be noted that the multi-phase motors are invariably supplied by power electronic converters since variable speed applications are sought. Thus the emphasis of the research on multi-phase electric drive is limited to the modelling and control of the power electronic converters such as inverters and matrix converters [7-17]. Initially, only two-level converters were used [6], and later on multi-level multi-phase converters is investigated [18]. Ward and Harer [19] proposed multiphase motor drives, but the research on it was slow in its release.

The research on multiphase drive systems has been significantly developed since the beginning of this century due to advancement in semi conductor devices and digital signal processors technologies. Detailed reviews on state-of-the-art multiphase drive research are available in [15]-[18] and [20]. It is to be emphasized here that ac/dc/ac converters generally supply the multiphase motors. Thus, the focus of the current research on multiphase electric drives is limited to the modeling and controlling of the power converters [21]-[26], [27], [28], [29]-[31]. Little effort is being made to develop static transformation system to change the phase number from three-to-n-phase (where $n>3$ and odd). An exception is [32], where a new type of transformer is presented, which is three-to-five-phase system. In [33] and [34], the au thors presented an interesting solution for three-to-five-phase conversion. At the end of [33], the authors briefly mention the seven-phase system; however, no study or analysis was done on three-to-seven-phase transformer.

Accordingly, this paper is based on the same principle as that of [32]. The analysis and design, however, are completely different. In our approach, in contrast to the system of [32], the phase angle between two consecutive phases is not an integer number. Multiphase, especially 6- and 12-phase, systems are found to produce less amplitude of ripples with higher frequency in ac de rectifier system [35]. Thus, 6- and 12phase transformers are designed to feed a multi-pulse rectifier system and the technology is matured. Recently, 24- and 36-phase transformer systems were proposed for supplying a multi-pulse rectifier system [36-39].

The reason of adopting a 6-, 12-, or 24-phase system is that these numbers are multiples of three and designing such system is simple and straightforward. However, increasing the number of phases certainly affects the complexity of the system. No such design is available for odd number of phases, such as 7, 11, etc., as far as is known to the authors. The usual practice for analysis is to test the designed motor for a number of operating conditions with pure sinusoidal supply [40]. Normally, no-load test, blocked rotor, and load tests are performed on a motor to determine its parameters. Although supply used for multiphase motor drives obtained from multi phase inverters could have more current ripples, there are control methods available to lower the current distortion below $1 \%$, based on application and requirement [25].

The machine parameters obtained using a PWM inverter may not provide the correct value. Thus, a pure sinusoidal supply system is required to feed the motor for better analysis. Accordingly, this paper proposes a special transformer connection scheme to obtain a balanced three-to-seven-phase supply with sinusoidal waveforms. The expected application areas of the proposed transformer are the electric power transmission system, power electronic converters (ac-dc and ac-ac), and the multiphase electric drive system. The fixed three-phase voltage and fixed frequency available in grid power supply can be transformed to fixed voltage and fixed frequency seven-phase output supply. Furthermore, the output magnitude may be made variable by inserting a three-phase autotransformer at the input side. In this paper, the input and output supply can be arranged in the following manners:

a. Input star, output star.

b. Input star, output heptagon.

c. Input delta, output star.

d. Input delta, output heptagon.

Since input is a three-phase system the windings are connected in usual manner. The output/secondary side star connection is discussed in the following sections. The heptagon output connection may be derived following a similar approach. Thus, only star output connection is discussed in the following section and other connections are omitted.

\section{WINDING ARRANGEMENT SEVEN-PHASE STAR OUTPUT}

Three separate iron cores are designed with each of them carrying one primary and four secondary coils, except in one core where five secondary coils are wound. Six terminals of primaries are connected in an appropriate manner resulting in star and/or delta connections, and the 26 terminals of secondary are connected in a different fashion resulting in a star or heptagon output. The connection scheme of secondary windings to obtain star output is illustrated in Figures. 1 and 2 and the corresponding phasor diagram is illustrated in Figure 3. The construction of output phases with requisite phase angles of $360 / 7=51.43$ 。 between each phase is obtained using appropriate turn ratios and the governing phasor equation is illustrated in (1c). The turn ratios are different in each phase as shown in Figure 1. The choice of turn ratio is the key in creating the requisite phase displacement in the output phases. The turn ratios between different phases are 
given in Table 1. The input phases are designated with letters " $X$," "Y," and " $Z$ " and the output are designated with letters "a," "b," "c," "d," "e," "f," and "g." The mathematical basis for this connection is the basic addition of real and imaginary parts of the vectors. For example, the solution for (1a) gives the turn ratio of phase "b," (Vb taken as unity)

$$
V x\left[\cos \left(\frac{2 \pi}{7}\right)+j \sin \left(\frac{2 \pi}{7}\right)\right]-V z\left[\cos \left(\frac{\pi}{21}\right)-j \sin \left(\frac{\pi}{21}\right)\right]=1
$$

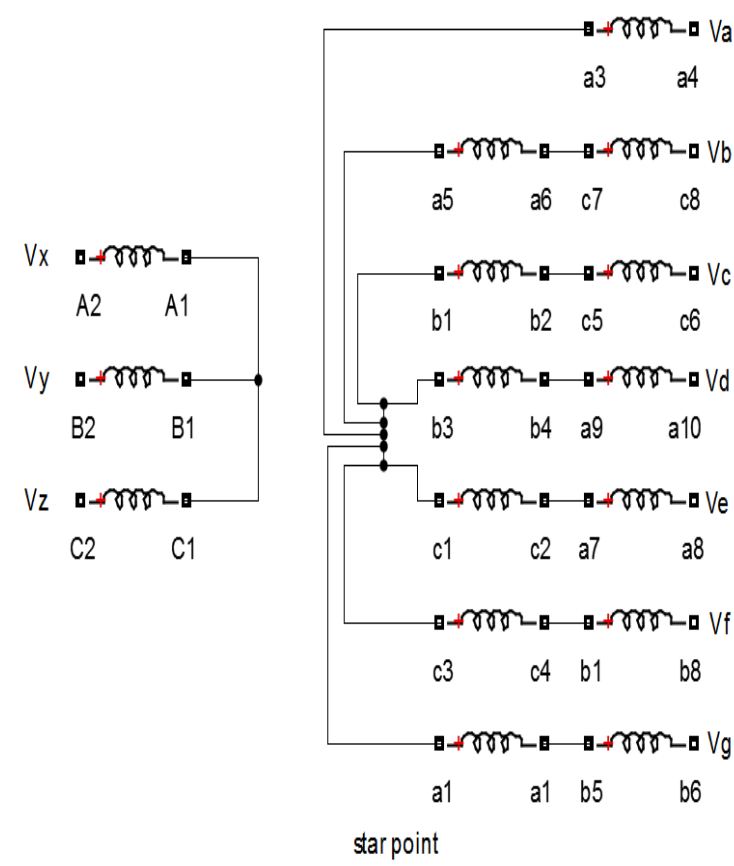

Figure 1. Proposed transformer winding connection (star)

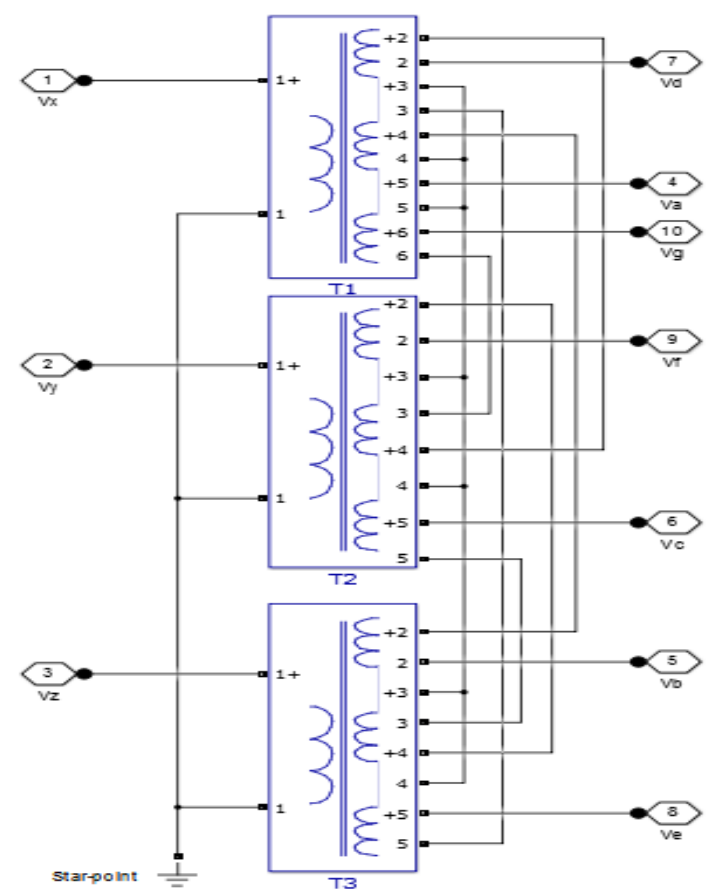

Figure 2. Proposed transformer winding arrangements (star-star) 


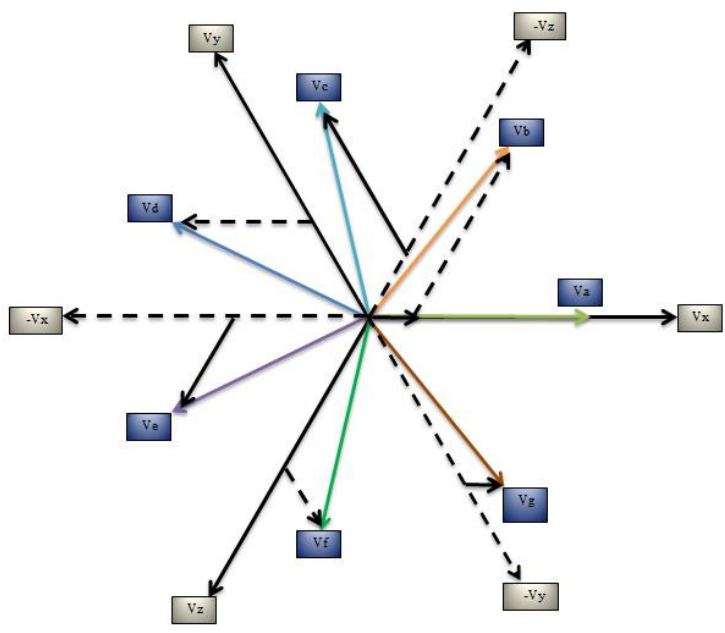

Figure 3. Phasor diagram of the proposed transformer connection (star-star)

Table 1. Turn Ratio Secondary Turns $\left(\mathrm{N}_{2}\right)$ to Primary $\left(\mathrm{A}_{1} \mathrm{~A}_{2}\right)$ Turns $\left(\mathrm{N}_{1}\right)$

\begin{tabular}{cccccr}
\hline Name of the winding & Turns ratio N2/N1 & Name of the winding & Turns ratio N2/N1 & Name of the winding & Turns ratio N2/N1 \\
\hline a1a2 & 0.1721 & $\mathrm{~b} 1 \mathrm{~b} 2$ & 0.7854 & $\mathrm{c} 1 \mathrm{c} 2$ & 0.5010 \\
$\mathrm{a} 3 \mathrm{a} 4$ & 1.0000 & $\mathrm{~b} 3 \mathrm{~b} 4$ & 0.5010 & $\mathrm{c} 3 \mathrm{c} 4$ & 0.7854 \\
$\mathrm{a} 5 \mathrm{a} 6$ & 0.1721 & $\mathrm{~b} 5 \mathrm{~b} 6$ & 0.9028 & $\mathrm{c} 5 \mathrm{c6}$ & 0.3404 \\
$\mathrm{a} 7 \mathrm{a} 8$ & 0.6505 & $\mathrm{~b} 7 \mathrm{~b} 8$ & 0.3404 & $\mathrm{c} 7 \mathrm{c} 8$ & 0.9028 \\
\hline
\end{tabular}

Equating real and imaginary parts and solving for $V_{x}$ and $V_{z}$ we get:

$$
\begin{aligned}
& |V x|=\left|\frac{\sin (\pi / 21)}{\sin (\pi / 3)}\right|=0.1721 \\
& |V z|=\left|-\frac{\sin (2 \pi / 7)}{\sin (\pi / 3)}\right|=0.9028
\end{aligned}
$$

The (1c) is the result of solutions of equations like (1a) for other phases. Therefore, by simply summing the voltages of two different coils, one output phase is created. It is important to note that the phase "a" output is generated from only one coil namely "a3a4" in contrast to other phases which utilizes two coils. Thus, the voltage rating of "a3a4" coil should be kept to that of rated phase voltage to obtain balanced and equal voltages.

$$
\begin{aligned}
& {\left[\begin{array}{l}
V a \\
V b \\
V c \\
V d \\
V e
\end{array}\right]=\frac{1}{\sin \left(\frac{\pi}{3}\right)} *} \\
& {\left[\begin{array}{ccc}
\sin \left(\frac{\pi}{3}\right) & 0 & 0 \\
\sin \left(\frac{\pi}{21}\right) & 0 & -\sin \left(\frac{2 \pi}{7}\right) \\
0 & \sin \left(\frac{5 \pi}{21}\right) & -\sin \left(\frac{2 \pi}{21}\right) \\
-\sin \left(\frac{4 \pi}{21}\right) & \sin \left(\frac{\pi}{7}\right) & 0 \\
-\sin \left(\frac{4 \pi}{21}\right) & 0 & \sin \left(\frac{\pi}{7}\right) \\
0 & -\sin \left(\frac{2 \pi}{21}\right) & \sin \left(\frac{5 \pi}{21}\right) \\
\sin \left(\frac{\pi}{21}\right) & -\sin \left(\frac{2 \pi}{7}\right) & 0
\end{array}\right] *\left[\begin{array}{l}
V x \\
V y \\
V z
\end{array}\right]}
\end{aligned}
$$


Where the three-phase voltages (line-to-neutral) are defined as:

$$
\begin{aligned}
& V_{j}=V_{\max } \sin \left(\omega t-n \frac{\pi}{3}\right) \\
& j=x, y, z, n=0,2,4 \\
& V_{k}=V_{\max } \sin \left(\omega t-n \frac{\pi}{7}\right), \rightarrow k=a, b, c, d, e, f, g \\
& \text { and } \rightarrow n=0,2,4,6,8,10,12
\end{aligned}
$$

Using (1c), a seven-phase output can be created from a three-phase input supply. A general expression for an " $n$ " phase system is derived and shown in (6). Since a transformer works as a two-port network, the reverse connection is also possible, i.e., if a seven-phase supply is given at the input the output can be three phase. This is especially important if electric power is generated using a seven-phase alternator and the supply to the grid is given as three phase. To obtain three-phase outputs from a seven-phase input supply, following relations hold good.

$$
\begin{aligned}
& {\left[\begin{array}{l}
V x \\
V y \\
V z
\end{array}\right]=\frac{1}{\sin \left(\frac{2 \pi}{7}\right)} *} \\
& {\left[\begin{array}{ccc}
\sin \left(\frac{2 \pi}{7}\right) & 0 & 0 \\
0 & 0 & 0 \\
0 & \sin \left(\frac{4 \pi}{21}\right) & 0 \\
0 & \sin \left(\frac{2 \pi}{21}\right) & 0 \\
0 & 0 & \sin \left(\frac{2 \pi}{21}\right) \\
0 & 0 & \sin \left(\frac{4 \pi}{21}\right) \\
0 & 0 & 0
\end{array}\right]^{t} *\left[\begin{array}{c}
V a \\
V b \\
V c \\
V d \\
V e
\end{array}\right]}
\end{aligned}
$$

\section{WINDING ARRANGEMENT SEVEN-PHASE DELTA OUTPUT}

Three separate iron cores are designed with each of them carrying one primary and four secondary coils, except in one core where five secondary coils are wound. Six terminals of primaries are connected in an appropriate manner resulting in delta connections, and the 26 terminals of secondaries are connected in a different fashion resulting in a star output. The connection scheme of secondary windings to obtain star output is illustrated in Figure 4.

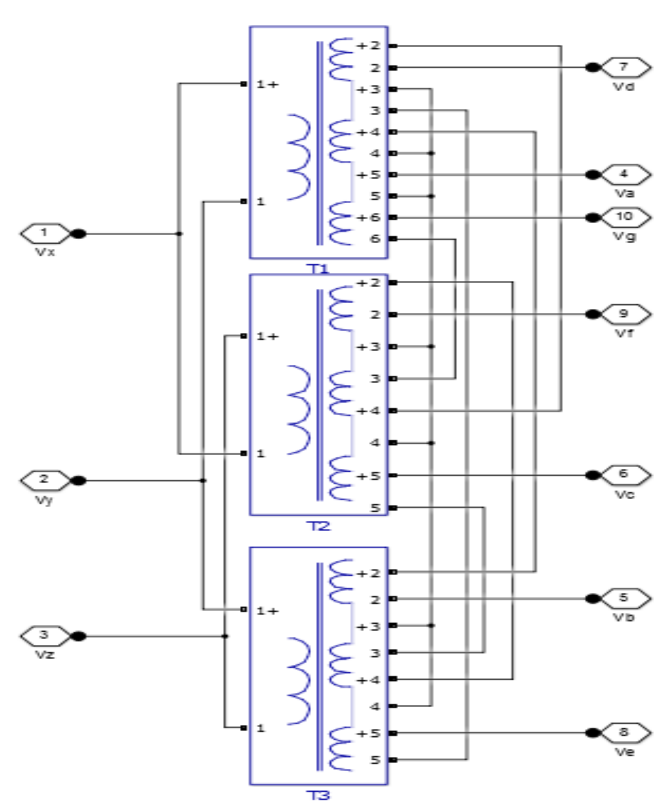

Figure 4. Proposed transformer winding arrangements (delta-star) 
The corresponding phasor diagram is illustrated in Figure 5. The construction of output phases with requisite phase angles of $360 / 7=51.43 \circ$ between each phase is obtained using appropriate turn ratios.

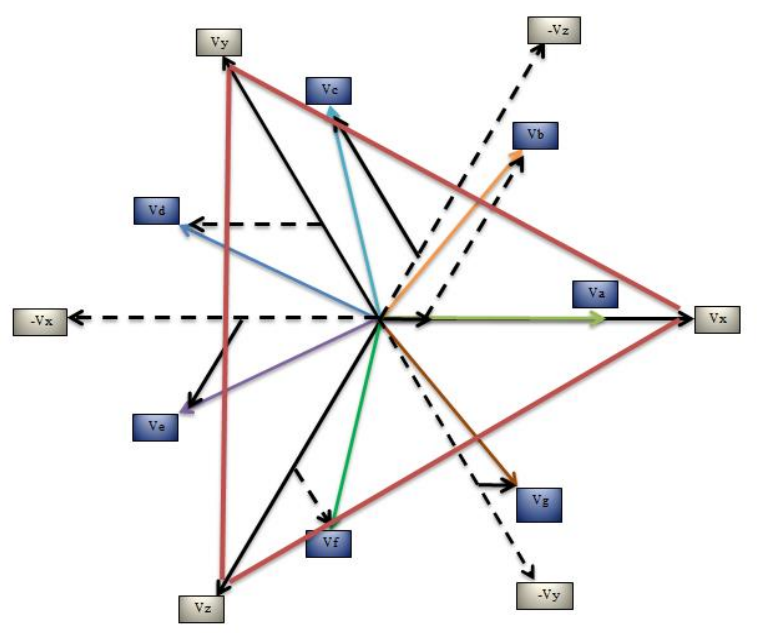

Figure 5. Phasor diagram of the proposed transformer connection (delta-star)

\section{WINDING ARRANGEMENT SEVEN-PHASE HEPTAGON OUTPUT}

The construction of output phases with requisite phase angles of $360 / 8=45 \circ$ between each phase is obtained using appropriate turn ratios. Three separate iron cores are designed with each of them carrying one primary and four secondary coils, except in one core where five secondary coils are wound. Six terminals of primaries are connected in an appropriate manner resulting in delta or star connections, and the 28 terminals of secondaries are connected in a heptagon output. Figure 6 show proposed transformer winding arrangements (star- heptagon). Table 2 show turn ratio secondary turns $\left(\mathrm{N}_{2}\right)$ to primary $\left(\mathrm{A}_{1} \mathrm{~A}_{2}\right)$ turns $\left(\mathrm{N}_{1}\right)$ star-heptagon and delta-heptagon [41].

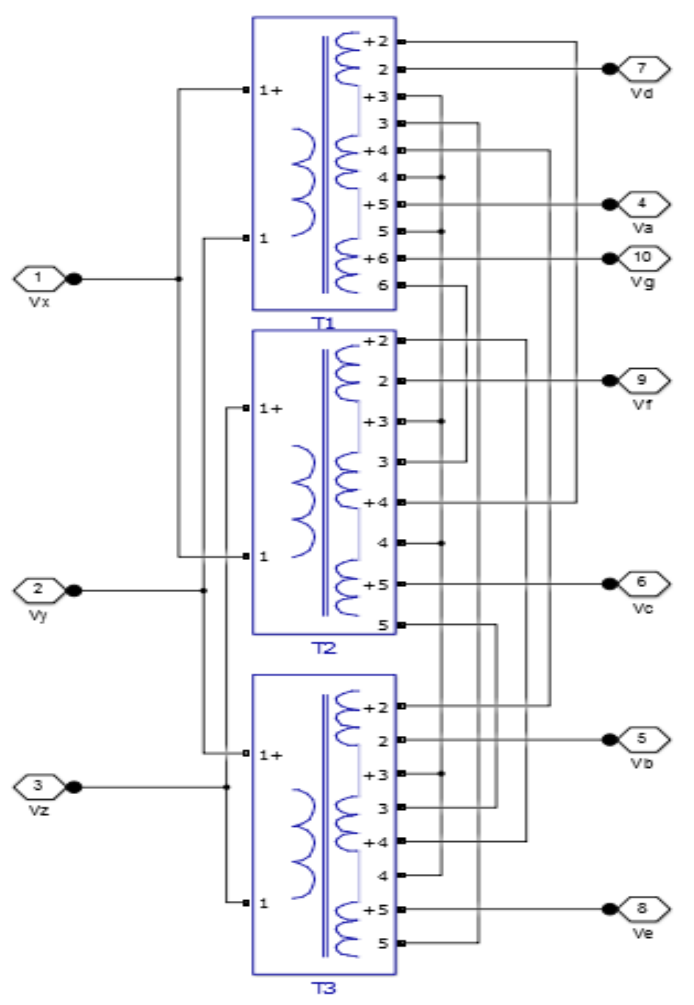

Figure 6. Proposed transformer winding arrangements (star- heptagon) 
Table 2. Turn Ratio Secondary Turns $\left(\mathrm{N}_{2}\right)$ to Primary $\left(\mathrm{A}_{1} \mathrm{~A}_{2}\right)$ Turns $\left(\mathrm{N}_{1}\right)$ Star-Heptagon and Delta Heptagon [41]

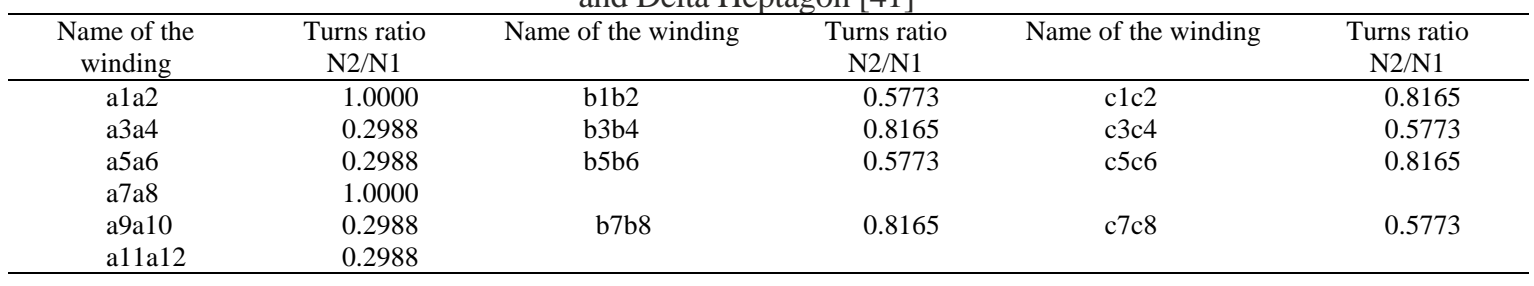

\section{SIMULATION RESULTS}

The designed transformer is at first simulated using "SimPowerSystem" block sets of the MATLAB/Simulink software. The inbuilt transformer blocks are used to simulate the conceptual design. The appropriate turn ratios are set in the dialog box and the simulation is run. Turn ratios are shown in Tables 1 and 2. The resulting input and output voltage waveforms are illustrated in Figure 7. It is seen that the output is a balanced seven-phase supply for a balanced three-phase input.

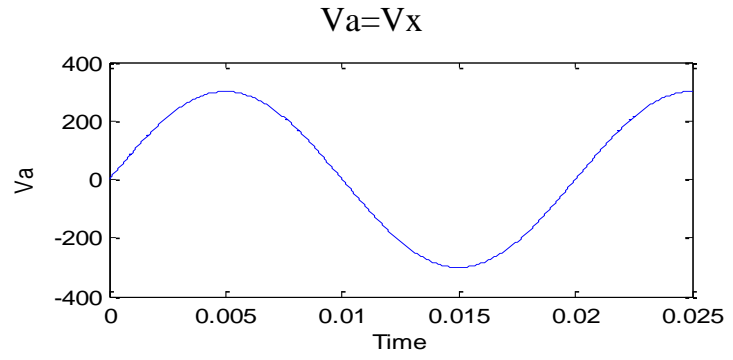

(a)

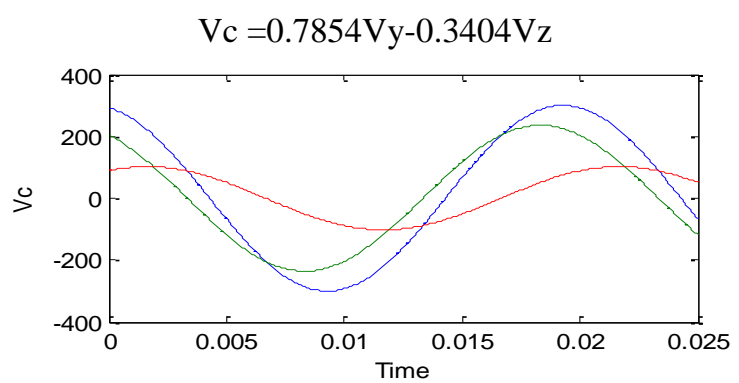

(c)

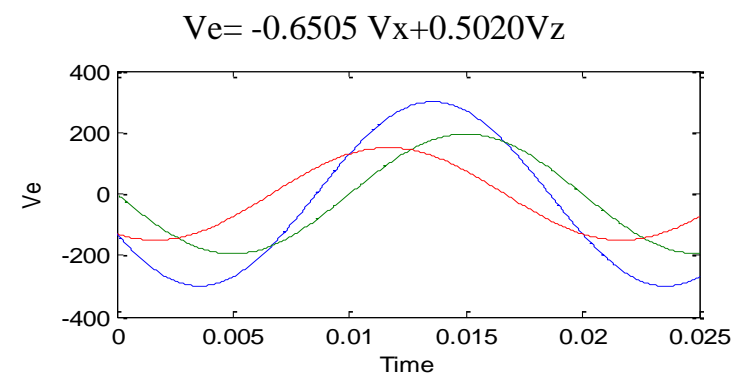

(e)

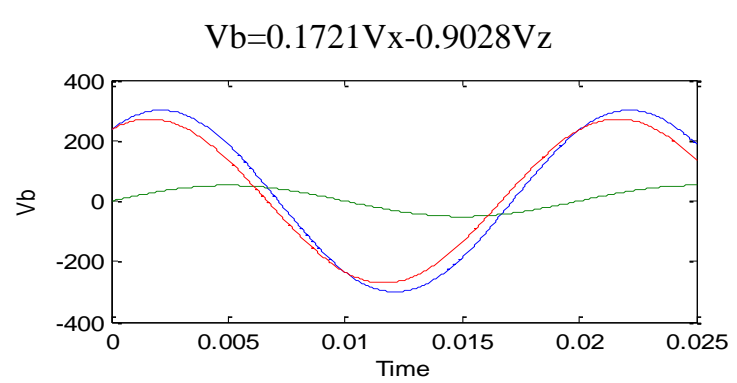

(b)

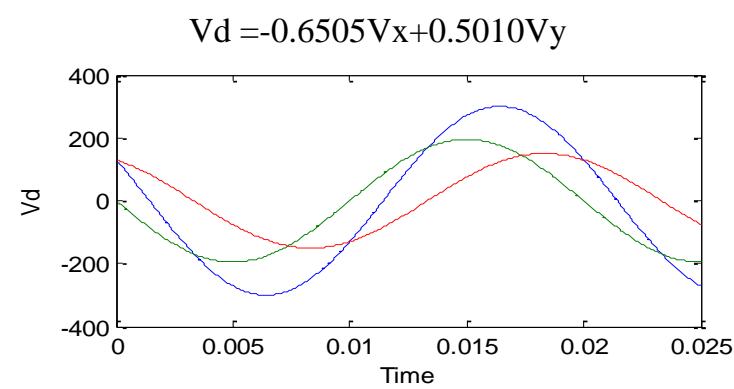

(d)

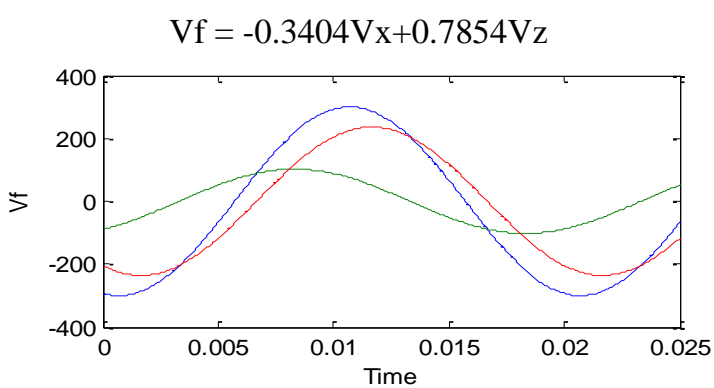

(f)

Figure 7. (a) Va output voltage and inputs $\mathrm{Vx}$, (b) Vb output voltage and inputs $\mathrm{Vx}$ and $-\mathrm{Vz}$, (c) Vc output voltage and inputs $\mathrm{Vy}$ and $-\mathrm{Vz}$, (d) Vd output voltage and inputs $-\mathrm{Vx}$ and $\mathrm{Vy}$, (e) Ve output voltage and inputs $-\mathrm{Vx}$ and $\mathrm{Vz}$, (f) Vf output voltage and inputs $-\mathrm{Vx}$ and $\mathrm{Vz}$, 


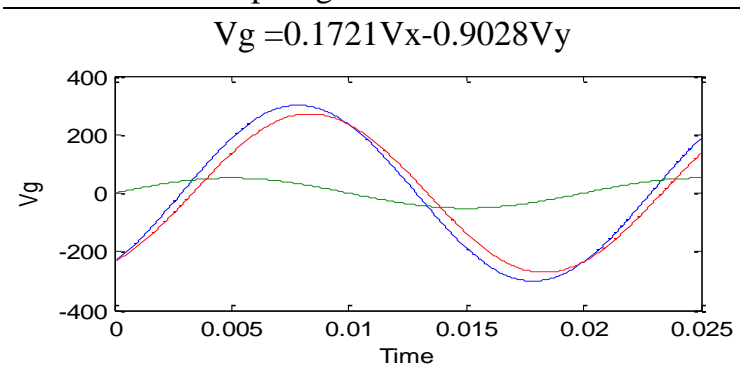

(g)

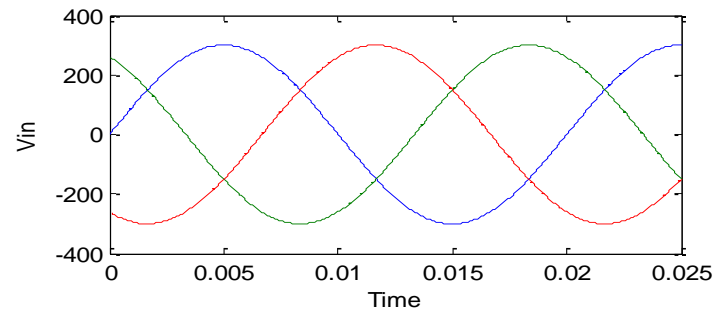

(h)

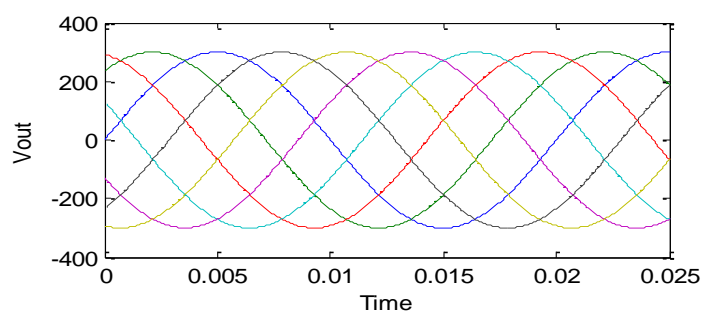

(i)

Figure 7. (g) Vg output voltage and inputs $\mathrm{Vx}$ and - Vy, (h) input voltage $\mathrm{Vx}$ and $\mathrm{Vy}$ and $\mathrm{Vz}$, (i) The output voltage $\mathrm{Va}, \mathrm{Vb}, \mathrm{Vc}, \mathrm{Vd}, \mathrm{Ve}, \mathrm{Vf}$ and $\mathrm{Vg}$

The output will be unbalanced if the input is unbalanced. The unbalancing study is out of the scope of this paper and will be dealt separately and reported in the future. Individual output phases are also shown along with their respective input voltages. The phase $\mathrm{Va}$ is not shown because $\mathrm{Va}=\mathrm{Vx}$, i.e., the input and the output phases are same. Figure 7 shows the reconstruction of seven-phase output waveform from a three-phase inputwaveform. The three-phase output from a seven-phase input supply can also be obtained in similar fashion.

\section{FFT ANALYSIS}

Fourier analysis is the process of representing a function in terms of sinusoidal components. It is widely employed in many areas of engineering, science, and applied mathematics. It provides information as to what frequency components represent a function. The FFT analysis gives the THD of the system to that of a fundamental value. Rate of harmonic generation in Star-Star mode very high and the rate of the harmonic in novel connection delta-star reaches to zero. Figure $8 \mathrm{a}$ and $8 \mathrm{~b}$ is THD measured at the position shown.
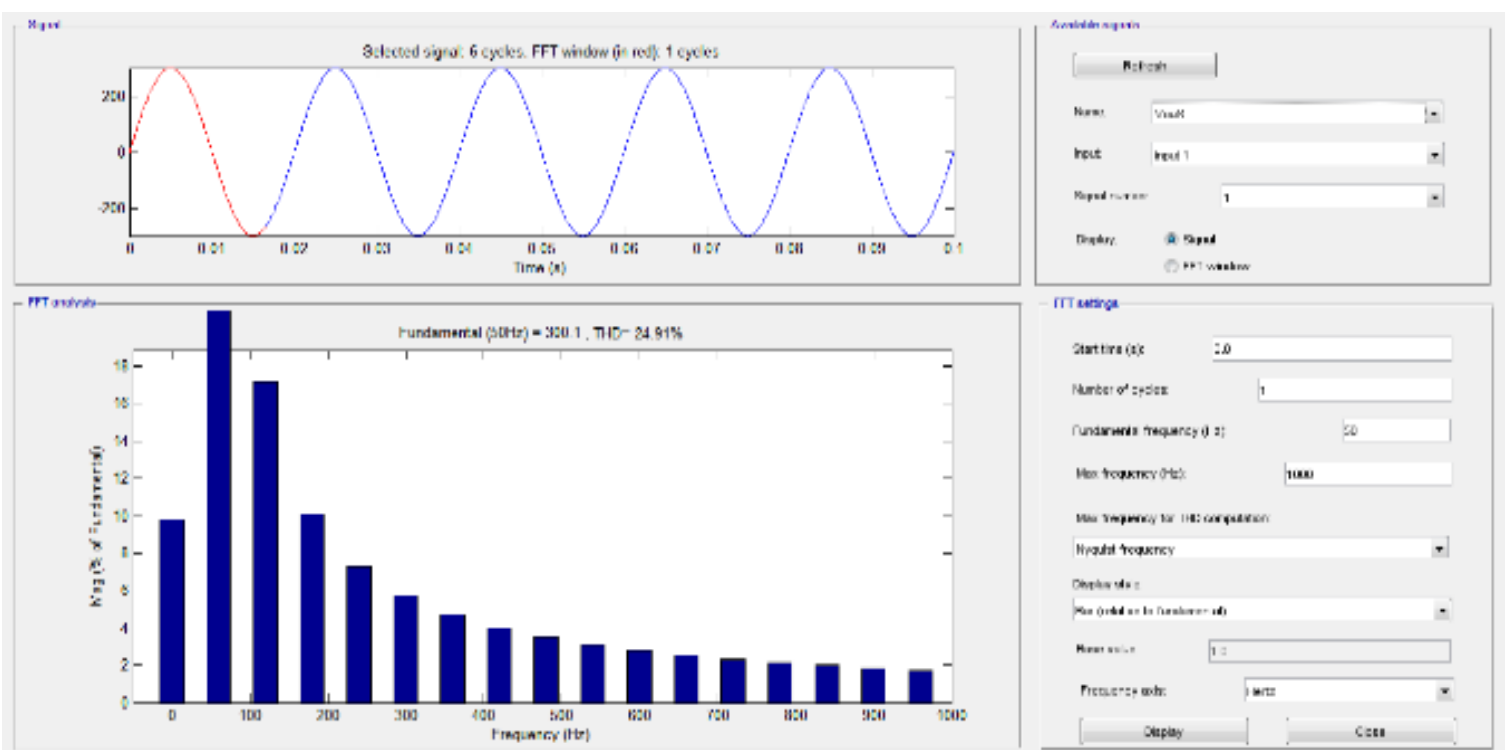

Figure 8a. The output voltage fundamental harmonics in the star-stars 


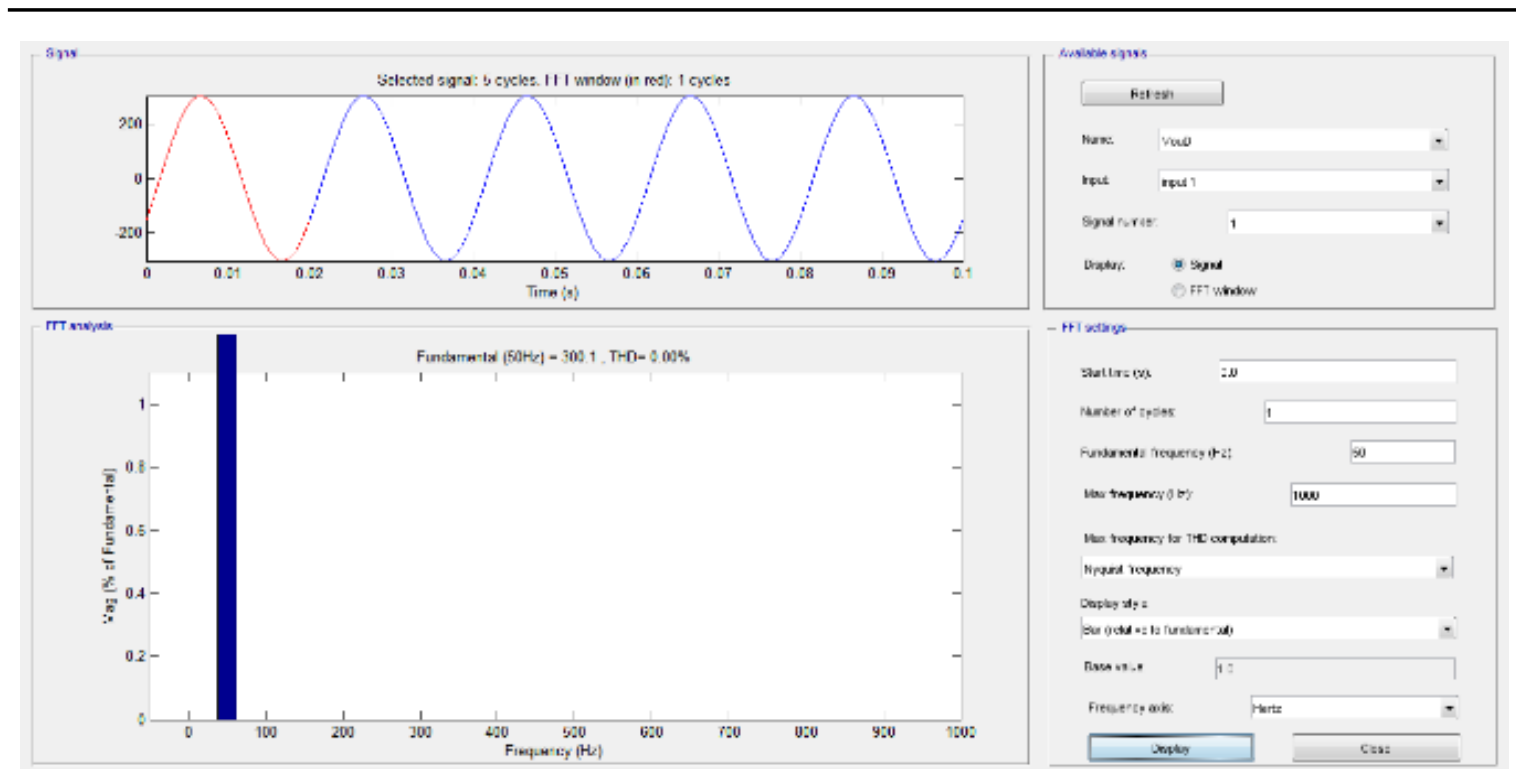

Figure $8 b$. The output voltage fundamental harmonics in the delta - stars

\section{CONCLUSION}

This paper gives a new method to convert 3 phase to 7 phase using special transformer connection. The winding arrangement and the vector diagram, along with the turn ratios, are given in the table. The successful implementation of the proposed connection scheme is elaborated upon using simulation of matlab software using simpower system blocks. The proposed connection scheme can be used in drives and other multiphase applications. By using the same method we can also get the heptagon output.

\section{REFERENCES}

[1] D. Basic, J.G. Zhu and G. Boardman, "Transient performance study of brushless doubly fed twin stator generator," IEEE Trans. On Energy Conversion, vol. 18, issue 3, pp. 400-408, 2003.

[2] L.A. Periera and V.M. Canalli, "Five-phase permanent magnet synchronous machine operating as generator design, parameter determination by FEM and performance," Proc. 37th IEEE Ind. Appl. Annual Society meeting IAS, vol. 1, pp. 398-405, 13-18, October 2002.

[3] J.R. Stewart and D.D. Wilson, "High phase order transmission- A feasibility analysis Part-I-Steady state considerations," IEEE Trans. On PAS, vol. PAS-97, issue 6, pp 2300-2307, Nov. 1978.

[4] J.R. Stewart and D.D. Wilson, "High phase order transmission- A feasibility analysis Part-II-Over voltages and insulation requirements," IEEE Trans. On PAS, vol. PAS-97, issue 6, pp 2308-2317, Nov. 1978.

[5] K.N. Pavithran, R. Parimelalagan and M.R. Krsihnamurthy, 'Studies on inverter fed five-phase induction motor drive," IEEE Trans. Power Elect. vol. 3, no. 2, pp. 224-235.

[6] A. Iqbal, S. Pyami, R.K. Behra, and A. Anad, "Field Oriented controlled Five-phase Induction motor drive with active front end rectifier," IEEE PECON, 2-5 Dec., Malaysia, CD-ROM, pp. 328-332.

[7] E. Levi, "Multiphase Electric Machines for Variable-Speed Applications" IEEE Trans on Ind. Elect., vol. 55, No. 5, pp. 1893-1909.

[8] J.R. Stewart andD.D.Wilson, "High phase order transmission-Afeasibility analysis-Part-II: Over voltages and insulation requirements," IEEE Trans. Power App. Syst., vol. PAS-97, no. 6, pp. 2308-2317, Nov. 1978.

[9] J. R. Stewart, E. Kallaur, and J. S. Grant, "Economics of EHV high phase order transmission," IEEE Trans. Power App. Syst., vol. -PAS 103, no. 11, pp. 3386-3392, Nov. 1984.

[10] S. N. Tewari, G. K. Singh, and A. B. Saroor, "Multiphase Power transmission research-A survey," Electr. Power Syst. Res., vol. 24, pp. 207-215, 1992.

[11] C. M. Portela andM.C. Tavares, "Six-phase transmission line-propagation characteristics and new three-phase representation," IEEE Trans. Power Delivery, vol. 18, no. 3, pp. 1470-1483, Jul. 1993.

[12] T. L. Landers, R. J. Richeda, E. Krizanskas, J. R. Stewart, and R. A. Brown, "High phase order economics: Constructing a new transmission line," IEEE Trans. Power Delivery, vol. 13, no. 4, pp. 1521-1526, Oct. 1998.

[13] J. M. Arroyo and A. J. Conejo, "Optimal response of power generators to energy, AGC, and reserve pool based markets,” IEEE Power Eng. Rev., vol. 22, no. 4, pp. 76-77, Apr 2002.

[14] M. A. Abbas, R. Chirsten, and T. M. Jahns, "Six-phase voltage source inverter driven induction motor," IEEE Trans. Ind. Appl., vol. IA-20, no. 5, pp. 1251-1259, Sep./Oct. 1984.

[15] K. N. Pavithran, R. Parimelalagan, and M. R. Krsihnamurthy, "Studies on inverter fed five-phase induction motor drive," IEEE Trans. Power Elect.,vol. 3, no. 2, pp. 224-235, Apr. 1988. 
[16] G. K. Singh, "Multi-phase induction machine drive research-A survey," Electr. Power Syst. Res., vol. 61, pp. 139-147, 2002.

[17] R. Bojoi, F. Farina, F. Profumo, and A. Tenconi, "Dual-three phase induction machine drives control—A survey," IEE J. Trans. Ind. Appl., vol. 126, no. 4, pp. 420-429, 2006.

[18] E. Levi, R. Bojoi, F. Profumo, H. A. Toliyat, and S. Williamson, "Multiphase induction motor drives-A technology status review," IET Electr. Power Appl., vol. 1, no. 4, pp. 489-516, Jul. 2007.

[19] E. E. Ward and H. Harer, "Preliminary investigation of an inverter-fed 5-phase induction motor," Proc. IEE, vol. 116, no. 6, pp. 980-984, 1969.

[20] G. K. Singh, K. B. Yadav, and R. P Sani, "Capacitive self-excitation in six-phase induction generator for small hydro power-An experimental Investigation, ”IEEE Conf. Power Electron., Drives Energy Syst. Ind.Growth [CD$R O M]$, New Delhi, India, Paper 5A-20, Dec. 2006.

[21] E. Levi, "Multiphase electric machines for variable-speed applications," IEEE Trans Ind. Elect., vol. 55, no. 5, pp. 1893-1909, May 2008.

[22] A. Iqbal and E. Levi, "Space vector PWMtechniques for sinusoidal output voltage generation with a five-phase voltage source inverter," Electr. Power Compon. Syst., vol. 34, no. 2, pp. 119-140, 2006.

[23] D. Dujic, M. Jones, and E. Levi, "Generalised space vector PWMfor sinusoidal output voltage generation with multiphase voltage source inverter," Int. J. Ind. Elect. Drives, vol. 1, no. 1, pp. 1-13, 2009.

[24] M. J. Duran, F. Salas, and M. R. Arahal, "Bifurcation analysis of fivephase induction motor drives with third harmonic injection," IEEE Trans.Ind. Elect., vol. 55, no. 5, pp. 2006-2014, May 2008.

[25] M. R. Arahal and M. J. Duran, "PI tuning of five-phase drives with third harmonic injection," Control Engg. Pract., vol. 17, no. 7, pp. 787-797,Jul. 2009.

[26] D. Dujic, M. Jones, and E. Levi, "Analysis of output current ripple rms in multiphase drives using space vector approach,” IEEE Trans. Power Elect., vol. 24, no. 8, pp. 1926-1938, Aug. 2009.

[27] M. H. Rashid, "Power Electronics Handbook: Devices, Circuits, and Applications, 3rd ed. Amsterdam," The Netherlands: Elsevier, 2011.

[28] M. Jones, "A novel concept of a multi-phase multi-motor vector controlled drive system," Ph.D. dissertation, School Eng., Liverpool John Moores Univ., School Eng., Liverpool, U.K., 2005.

[29] M. Jones and E. Levi, "A literature survey of the state-of-the-art in multiphase ac drives," in Proc. Int. UPEC, Stafford, U.K., pp. 505-510, 2002.

[30] A. Iqbal and E. Levi, "Space vector modulation schemes for a five-phase voltage source inverter," presented at the Eur. Power Electron. Conf. [CD-ROM], Dresden, Germany, Paper 0006.pdf, 2005.

[31] H. M. Ryu, J. H. Kim, and S. K. Sul, "Analysis of multi-phase space vector pulse width modulation based on multiple d-q spaces concept," presented at the Int. Conf. Power Electron. Motion Control [CD-ROM], Xian, China, Paper 2183.pdf, 2004.

[32] M. Correa, C. R. da Silva, H. Razik, C. B. Jacobina, and E. da Silva, "Independent voltage control for seriesconnected six-and three-phase Induction machines," IEEE Trans. Ind. Appl., vol. 45, no. 4, pp. 1286-1293, Jul./Aug. 2009.

[33] M. El Kahel, G. Olivier, C. Guimaraes, and G. E. April, "Five and seven phase converter transformers," in Proc. CCECE and IEEE Conf., Montreal, QC, Canada, pp. 708-711 (in French), 1995.

[34] M. El -Kahel, G. Olivier, and A. O. BA, "Five and seven phases converters: A feasibility study, " in Proc. CCECE \& IEEE Conf., Calgary, pp. 1000-1003 (in French), 1996.

[35] P. C. Krause, “Analysis of Electric Machinery,” New York:McGraw-Hill, 1986.

[36] A. Iqbal, S. Moinuddin, M. R. Khan, SK. M. Ahmed, and H. Abu-Rub, "A novel three-phase to five-phase transformation using special transformer connection," IEEE Trans. Power Delivery, vol. 25, no. 3, pp. 1637-1644,Jun. 2010.

[37] S. Choi, B. S. Lee, and P. N. Enjeti, "New 24-pulse diode rectifier systems for utility interface of high power AC motor drives," IEEE Trans. Ind. Appl., vol. 33, no. 2, pp. 531-541, Mar./Apr. 1997.

[38] V. Garg, B. Singh, and G. Bhuvaneswari, "A tapped star connected autotransformer based 24-Pulse AC-DC converter for power quality improvement in induction motor drives," Int. J. Emerg. Electr. Power Syst., vol. 7, no. 4, article 2, 2006.

[39] B. Singh and S. Gairola, “An autotransformer based 36 pulse controlled ac-dc converter," IETE J. Res., vol. 54, no. 4, pp. 255-262, 2008.

[40] B. Singh and S. Gairola, "A 24 pulse AC-DC converter employing a pulse doubling technique for vector controlled induction motor drives," IETE J. Res., vol. 54, no. 4, pp. 314-322, 2008.

[41] M. Tabrez, P. K. Sadhu and A. Iqbal, “ A Novel Three Phase to Seven Phase Conversion Technique Using Transformer Winding Connections," Engineering, Technology \& Applied Science Research, Vol. 7, No. 5, pp. 1953-1961, 2017. 